\title{
Moderating Role of Person Job-Fit Facet between Hierarchical Plateau and Turnover Intention
}

\author{
Ramesh Kumar * Waqar Akbar ${ }^{\dagger} \quad$ Naveed R. Khan ${ }^{\ddagger}$
}

\begin{abstract}
This study aims to examine the impact of hierarchical plateau on turnover intention with moderating role of person job-fit facet. Hierarchical plateau is a point of an individual's career life where the probability of being promoted further is low. The theory of work adjustment (TWA) is applied in this research study which measures that satisfaction level of an employee and leaving a company when needs and desired system of the person and the organization system mismatched at the workplace. Overall 260 employees participated by filling the self-administrated questionnaires from three different industrial sectors of Karachi, Pakistan including banking sector, pharmaceutical and insurance employees but result of completely and accurately filled questionnaires of 223 employees were tested. The results are generated through using Structural Equation Modeling (PLS-SEM) technique. The results show that hierarchical plateau has positive impact on turnover intention. However, moderating role of person job fit facet (neither demand abilities nor need supplies) moderates' relationship between independent and dependent variable. This study provides a model to management leaders and practitioners who can extremely look into this growing issue not only in Pakistan but worldwide. Certain actions need to be implemented by management to foster a positive attitude towards turnover intention through proper recruitments, development strategies and career training programs over the span of time. Furthermore, the study also provides the guidelines to HR departments to design the policies to resolve hierarchical plateau issues in their organization.
\end{abstract}

Keywords: Hierarchical plateau, turnover intention, person job fit, demand abilities, need supplies

\section{Introduction}

Experimental evidences show that companies that effectively hold their key employees will essentially flourish (Holtom, Mitchell, Lee, \& Inderrieden, 2005). Researchers and experts accept that human capital is the most significant advantage for a company, the retention of good gifted employees has consistently been one of the significant challenges. It has been noticed that high willful turnover hampers the key objectives of companies and turns into an extreme loss to their management. Unquestionably, the loss of high skilled employee not just makes financial figures down (Juhdi, Pa'wan, \& Hansaram, 2013), but it influences

\footnotetext{
${ }^{*}$ Faculty of Management Science, Shaheed Zulfikar Ali Bhutto Institute of Science \& Technology, Pakistan.

${ }^{\dagger}$ Faculty of Management Science, Shaheed Zulfikar Ali Bhutto Institute of Science \& Technology, Pakistan.

$\ddagger$ Department of Management Studies, Bahria University, Pakistan. Email: naveed.r.khan@gmail.com
} 
the profitability of the company, low determination of potential employees and loss of organizational vision. The cost required in every employee development is comparable to around $25 \%$ to $33 \%$ of the yearly salary of everyone who leave organization (Bitzer \& Van Der Smagt, 2006). Rahman, Naqvi, and Ramay (2008) studied turnover intentions in the Pakistani industry and found that job satisfaction negatively influences turnover intentions. Regardless of the extreme results, companies around the world are always confronting a high number of intractable turnovers. The drawbacks in the retention procedure of the companies could be one reason for such high pace of turnover intention. To put it simple, it might be conceivable that chosen people who don't fit with the company's environment, and, at last, choose to leave that company for a better fit. Past investigations uncovered that the presence of fit with successively good attitudes, more remarkable prosperity.

Hierarchal plateau is characterized as the point in an employee's career at which future promotions are somehow seems impossible in a current organization (Ference, Stoner, \& Warren, 1977). Various decisions and situations by top management are unavoidable in light of the hierarchical level in an organization. While examining the banking sector, Ghayas, Siddiqui, et al. (2012) found significant bond between the dimensions of the turnover intention and promotion in banking industry of Pakistan. Additionally, promotion is a significant predictor to reduce turn over intention of bankers. Taken together, for all employees' professional success as far as future promotions have turned out to be high focused and of high importance. Thus, more employees will arrive at a various plateau levels before achieving their profession objectives. So in order to decrease or dispose of the negative impacts of turnover intentions, researchers have put endeavors to discover directing factors impacting those intentions and the elements incorporating individual factors. For example, skills inspiration and job control, work related factors, coaching others, work scope, job vagueness, and manager's support. Few investigations have found out the limit criteria for staying away from the adverse impacts of various hierarchical plateaus, utilizing an individual circumstance connection approach. A large number of the past research on hierarchical plateau is inductive in nature, with researchers clarifying examples of connections without a proper hierarchical structure.

In the present technological world, it is essential to hold qualified workforce in the company since those employees have more significant levels of importance and authoritative learning. It is so expensive to replace those employees having high levels of skills (Ertürk \& Vurgun, 2015). The significant company's environment factors and reward frameworks may contribute both to the employees' fulfillment and job fit. Main point here is that those individual are generally the ones who have more elevated levels of person job fit and they will leave their organizations in the event when they are dealt unreasonably. The work environment elements which can lighten the impact of such conduct on employees' retention is still remained unexplored (Bani-Melhem, Quratulain, \& Al-Hawari, 2020). Regardless of the extreme results, organizations around the world are continually confronting a high number of turnover intentions. Another important area of discussion is Person job-fit facet is characterized as demands between the abilities and needs of a career, or between the wants of an employee and the provisions of work. Person job fit shows the general correspondence between the activity support framework and the need arrangement of the employee. The aggressive reactions of one feature of fit between the employee and the workplace can be 
supported by the general understanding between the employee and job. Accordingly, it is rational to recommend that person job fit facet will direct the connection between various hierarchical plateau and job satisfaction as shown in below figure 1. Kremer, Brannen, and Glennerster (2013) expressed that the impacts of various hierarchical plateaus on an employee's job fit and satisfaction levels.

While contributions by many researchers concerning on hierarchical plateau and turnover intentions have been done in the past. Few common reasons for success of a company are how good organization in managing highly skilled experienced employees at workplace by providing them due promotions at specific period of time (Lin, Chen, \& Lai, 2018). Considering all the above limitations and gaps, the current study is an attempt by applying the theory of work adjustment towards filling out the theoretical gaps that are still untaken and will be examining that how hierarchical plateau leads to turnover intention of employees. Additionally, moderating impact of demand abilities and need supplies of person job fit facet is checked to see the significant impact on employees' thought process which finally forced them to take turnover decision.

\section{Literature Review and Hypothesis Development}

The theory of work adjustment (TWA) was introduced to address the issues of how the communication between the employees and the job impacts the company's decisions leading to employee's turnover. To address the issue, the present study attempts to extend research in several aspects by adopting underpinning theory of TWA (Lofquist \& Dawis, 1984) which measures that satisfaction level and leaving company when need and desired system of the person and the organization system not matching at workplace. Earlier researches demonstrate a significant contributions in proposing that successively unsatisfied hierarchical employees think to leave their organization (Drucker-Godard, Fouque, Gollety, \& Le Flanchec, 2015). Hierarchical plateau thus portrays a phase in the career wherein an employee sees a low probability of accepting a desired promotions or an absence of employment challenges in their job. Hierarchical plateau doesn't suggest any cynicism; it is just observed as a phase one may reach in one's career (Veiga, 1981) where individual feels uncomfortable and does not enjoy his job at workplace. There are many reasons of such burnout leading to turnover intention and different facets play a significant role which contributes to it. Despite of such findings, there is no clarification that why anyone at different hierarchical plateau have difficult impacts on employees, nor is it clear whether hierarchical plateau applies negative consequences for all such employees in the same way (McCleese \& Eby, 2006). Understanding the systems of the plateau outcome relationship, and the contingent factors that may reinforce, is essential for researchers to pick knowledge into how the negative results of hierarchical plateau may be reduced. Aside from an examination, no exploration to date has investigated hierarchical plateau and employment frames of mind over various levels. 


\section{Hierarchical Plateau and Turnover Intention}

The hierarchical plateau is the time when a profession ends up standard and becomes exhausting, with the probability of not getting further promotions at workplace (Xie, Xin, \& Bai, 2016). It has been recommended that many individuals ace their employments after around three years at work, after which they should be given new challenges if the activity is to remain satisfying. Employees' turnover is a serious issue especially in the field of HR management. As a rule, arriving at an occupation job level is viewed as unfortunate and distressing, and is related with negative work temperament. Employment disappointment that prompts withdrawal has high turnover. The overall job of the activity level as a predecessor of both turnover and early retirement stays vague. The significance of the hierarchical plateau level as a supporter of withdrawal choices might be remarkable for more specialists who can stand to resign, or for any employee whose activity level is identified with a long haul decrease in new opportunities. There is proof that a capacity to keep learning and creating is identified with an inclination for deferring turnover (Afsar, Shahjehan, \& Shah, 2018).

In Pakistan banking sector, insurance and pharmaceuticals companies are growing at an accelerated pace. Currently, these are considered dynamic sectors both for the employees and employers; as per recent studies turnover ratio has significantly increased due to hierarchical plateau (Awan \& Tahir, 2015). In the broad category, empirical investigations have demonstrated that individuals who have an extraordinary good job fit have higher degrees of job satisfaction, organizational responsibility, and hierarchical recognizable outcomes and expanded work execution, resulted diminished turnover goals and real turnover intentions (Atitsogbui \& Amponsah-Tawiah, 2019). Different scholars have exhibited that hierarchical plateau could be utilized as a compelling instrument for procuring and choice of employees. Despite the fact that there is no general agreement on the determinants of turnover aim, person-job fit is exhibited to have profoundly related with goal to leave. For example, an examination among employees in a marketing department to analyze how P-J fit, character and hierarchical job affect aim to keep working with a company. By and large, the outcomes uncovered a factually huge connection between the hierarchical plateau and turnover intention. The employee's low plateau of fit with a job will reasonably or by implication cause more turnover intention.

\section{H1: Hierarchical plateau has positive impact on employees' turnover intention.}

\section{Person Job-Fit Facet (P-J Fit)}

Notwithstanding, organizational commitment mostly intervened P'J fit and goal to keep working with a company. Along these lines, as organizational commitment expanded, expectation to keep working with a company similarly expanded (Lin et al., 2018). This infers, when employees' information, skills and abilities fit the prerequisites of the work, or when their convictions and qualities are like that of the company, their dedication increases and they are less inclined to leave. In actuality, Chang, Chi, and Chuang (2010) watched a constructive connection between person-job fit and turnover intention. Their outcomes propose that an employee whose information and abilities don't coordinate the demands 
of the job is successively likely to find options somewhere else which may flood their apparent job versatility and subsequently increment aim to leave. Likewise, person-job fit will be definitely connected to work satisfaction and contrarily connected with turnover intention. While organizational job was likewise found to have affected the connection between person-job fit and purpose to stop. What's more, researchers opined that P-J fit is instantly recognizable from P-O fit and ought to be dealt with independently in an investigation and in many events uncorrelated when analyzed simultaneously (Lauver \& Kristof-Brown, 2001). In the meta-analysis study directed by Kristof-Brown, Zimmerman, and Johnson (2005), it was seen that there was a connection between person job fit and turnover intention. On the research of bank employees, it discovered that the turnover intention has diminished with the expansion in person job fit (Patra et al., 2015). In a study that individual job fit affected the turnover intention in a contrarily and primarily way. In the overview study of employees in a department, (Wurzelbacher et al., 2016) found out that person job fit affected the turnover expectation badly. Therefore, impact of Person Job fit facet as a moderating variable has been taken to check its relationship between independent and dependent variables. Person job fit consists of two elements i-e need supplies and demand abilities which are elaborated below.

\section{Needs-Supplies Fit (N-S Fit)}

This type of P-J fit has to do with the enthusiasm of the employees being in arrangement with what the job or the company brings to the table. N-S fit can be eluded as how much employee's needs, desires and fondness are satisfied by the job they perform and by the benefits related with that job (Chi \& Pan, 2012). There is a match between the wants of a employees and what the employees expect from their position, and when the employee's needs, wants, or inclinations are met by the job that they perform. When the employee needs and wants are met by the job or companies all things considered are going to be in right direction. N-S fit happens when employees' desires are satisfied by the job which they perform. Desires could come in various manners; it could be through hierarchical success and movement, promotions, interest and inclusion, pay scales and motivations. These could vary for various employees at various points in time and stage in their hierarchical. In N-S fit, the employees see, as per their own qualities, that their needs are steady with remunerations. For example, challenging job, open doors for promotion, gratefulness, savings and great working conditions. Other is requirements for independence and control, requirement for company help and significance that have been seen by past examinations to be vital influencers of job satisfaction, employee responsibility and retention in a company (Tetrick \& LaRocco, 1987).

H2: Person Job-fit facet (Need Supplies) moderates the relationship between hierarchical plateau and employees' turnover intention.

\section{Demand-Abilities Fit (D-A Fit)}

Demand abilities fit has to do with the employee's information, skills and abilities coordinating with what their job and what is actually required. That is, knowing whether the 
employees bring to the table in type of skills, information and ability is in line and couple with what the job or obligation requires. Demand abilities fit alludes to the degree to which job prerequisites coordinate the skills and abilities of employees. The Theory of Work Adjustment (Bretz Jr, Boudreau, \& Judge, 1994) underline that people will contribute longer in their jobs when there is D-A fit, and the activity condition encourages the utilization of their aptitudes and capacities. Similarly, individual take an attempt at fit between their very own apparent capacities, work requests and job assets (Greguras \& Diefendorff, 2009). Even though business practitioners agree that perceived demand abilities fit is related with positive job results, some fit investigations have neglected to discover experimental hold for this relationship. Demand Abilities fit as an element of person fit adds to a conviction that the workplace is helpful for what the organization needs. Work jobs that are lined up with people's capacities and self-ideas ought to be related with increasingly significant work experiences (Zhu, May, \& Avolio, 2004). Satisfying jobs that are consistent with a person's qualities adds to the experience of significant work and commitment.

H3: Person Job-fit facet (Demand Abilities) moderates the relationship between hierarchical plateau and employees' turnover intention.

\section{Research Model}

The model in Figure 1 shows the conceptual framework of this study. Hierarchical plateau (H1), which is the independent variable, has a positive impact on turnover intention of employees. Additionally, person job-fit facet is the moderator in the relationship between hierarchical plateau and turnover intention showing need supplies (H2) and demand abilities (H3) have positive impact on turnover intention.

\section{Methodology}

This study requires testing of the different hypotheses therefore; a quantitative approach is more suitable. Also, previous researches conducted on similar topics have also been conducted quantitatively. The cross-sectional study was conducted in Karachi, Pakistan and responses from employees of different industry knowledge workers of banking, insurance and pharmaceutical personnel were gathered. A simple random sample was selected for data collection and analysis because target audience was employees who have completed at least three years on the same position in the above-mentioned industry sectors. Total 300 close ended questionnaires were distributed through the help of HR departments / concern supervisors to keep confidentiality of all employees and answers were not disclosed to anyone. After one week a request reminder was also sent to those who did not submit the questionnaires. Finally, 223 questionnaires were ready for testing. The final responses were analyzed using Smart PLS software (Ringle, Wende, \& Becker, 2015). To calculate sample size, we require the number of indicators x 10 respondents as suggested (Hair Jr, Hult, Ringle, \& Sarstedt, 2016). The present study has 19 indicators so minimum sample size should be 190 . However, we have collected 223 which is above the threshold. 
Figure 2

Conceptual Framework

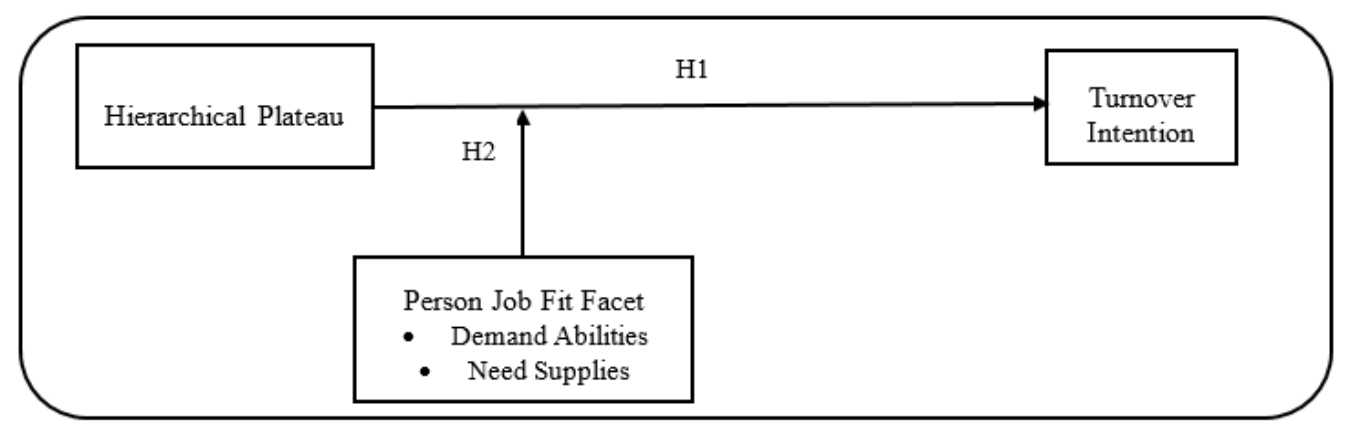

\section{Measurement of the Variables}

Hierarchical Plateau: Participants were asked to rate the extent on five-item scale to which employees is involved in a series of behaviors related to varying aspects of hierarchical plateau. Scales was adopted from Hossain and Shirazi (2018) ranging from 1 (strongly disagree) to 5 (strongly agree). The scales have also been previously used to measure impact of hierarchical plateau. An example of a question asked in the scale is "I believe that I have been in the same level for much too long".

Need Supplies: Need supplies was measured on four-item scale adopted from Ab Hamid, Sami, and Sidek (2017), by asking the employees to give their opinion with scales ranging from 1 (strongly disagree) to 5 (strongly agree). The scales have also been previously used to measure impact of need supplies. An example of a question asked in the scale is "The organization I currently work for gives me just about everything I could ask out of an organization."

Demand Abilities: Demand abilities was also adopted from Ab Hamid et al. (2017) by asking the employees to give their rating on a five-item scale adopted, with scales ranging from 1 (strongly disagree) to 5 (strongly agree). The scales have also been previously used to measure impact of demand abilities. An example of a question asked in the scale is "My skills and abilities are matched those required by my organization"

Turnover Intention: Turnover Intention was measured on five-item scale adopted from Memon, Salleh, Baharom, and Harun (2014) by asking the participants to give their opinion with scales ranging from 1 (strongly disagree) to 5 (strongly agree). In particular, the factors are more towards leaving organization when one doesn't get further promotions due to several reasons. The scales have also been previously used to measure impact of turnover intention. An example of a question asked in the scale is "I am currently considering leaving my current job to work at another company." 


\section{Demographics}

A review of the profiles given in Table 1 below highlights the fact that the majority of the respondents were male (56.5\%). Age group highlights the fact that the majority of the respondents are in the age group of 25 to 34 years (48\%). Table 2 represents that highest number of Managers (30\%) are willing to leave organizations as they don't find themselves a better future or further promotions in an existing company.

Table 1

Demographics

\begin{tabular}{lcc}
\hline Categories & & Percent \\
\hline Gender & Male & $56.50 \%$ \\
& Female & $43.50 \%$ \\
Age & Under 24 & $2 \%$ \\
& $25-34$ & $48 \%$ \\
& $35-44$ & $43 \%$ \\
& Above 44 & $7 \%$ \\
\hline
\end{tabular}

\section{Results}

The required data was collected with the help of close-ended questionnaires, coding and organization of data was properly done in order to have accurate results. The observations derived are presented in two divisions (Chin et al., 1998). The first part focuses on the reliability and validity of the scales because it is important to check the validity of the measurement models before beginning to analyze the hypothesis (Bollen \& Busse, 2001). The second part focuses on the assessment of the structural equation model.

Table 2

Designations

\begin{tabular}{lcc}
\hline & Frequency & Percent \\
\hline Officer & 43 & $20 \%$ \\
Assistant Manager & 55 & $25 \%$ \\
Manager & 68 & $30 \%$ \\
Senior Manager & 34 & $15 \%$ \\
General Manager and Above & 23 & $10 \%$ \\
\hline
\end{tabular}

\section{Factor Loadings, Composite Reliability, Convergent and Discrimi- nant Validity}

The validity of the measurement model refers to the fact that whether the markers of a variable measure what they are due to measuring whereas reliability provides internal consistency of scale. Measurement model considers loadings, composite reliability and convergent validity and Discriminant validity. Outer Loadings measures if all the items are significantly loaded on their respective constructs and should be 0.7 or higher, with a range of 0.6 to 0.7 being acceptable. Table 3 provides the Outer Loadings of all the 19 constructs used in the study. Other than HP1, HP2 and NS4 all the indicators have a loading of 0.70 and above. All the 19 variables have a loading of over 0.5 which is acceptable. Composite reliability is also calculated that shows the internal stability and 
uniformity of each construct and assesses the overall reliability of all the markers of the same construct. (Chi \& Pan, 2012) have proposed the composite reliability value of 0.7 to be acceptable. Table 2 highlights that the composite reliability of all the constructs used in this study is above 0.7. For average variance extracted (AVE), Fornell and Larcker (1981) suggest 0.5 as acceptable for AVE. Table 2 shows the AVE values for all the constructs used in this study are in the acceptable range.

Table 3

Factor Loadings, Composite Reliability, and Convergent Validity

\begin{tabular}{lcccc}
\hline Construct & Item & Loadings & CR & AVE \\
\hline Demand Abilities & DA1 & 0.801 & 0.895 & 0.632 \\
& DA2 & 0.809 & & \\
& DA3 & 0.728 & & \\
& DA4 & 0.768 & & \\
Hierarchical Plateau & DA5 & 0.861 & & \\
& HP1 & 0.699 & 0.869 & 0.574 \\
& HP2 & 0.692 & & \\
& HP3 & 0.871 & & \\
Heed Supplies & HP4 & 0.859 & & \\
& HP5 & 0.636 & & 0.509 \\
& NS1 & 0.724 & 0.805 & \\
NS2 & 0.732 & & \\
& NS3 & 0.759 & & \\
& NS4 & 0.634 & & \\
TI1 & 0.914 & 0.955 & 0.808 \\
& TI2 & 0.879 & & \\
& TI3 & 0.904 & & \\
& TI4 & 0.895 & & \\
TI5 & 0.901 & & \\
\hline
\end{tabular}

Discriminant Validity, observes how easily two dissimilar constructs can be differentiated. It is measured through cross loading and Fornell-Larcker Test. Appendix shows the cross-loadings of all the constructs that are part of this study and the results are in acceptable limits since the items are loaded highest on their own construct only. Another measure of Discriminant validity is the Fornell-Larcker Criterion. Ab Hamid et al. (2017) explains that this method compares the square root of the average variance extracted (AVE) with the correlation of constructs. A construct should always better explain the variation of its markers than the markers of other constructs. As a result, the square root of each construct's AVE should have a higher value than those with other constructs. Table 4 shows the result of this measure for this study and are acceptable. Another measure to establish discriminant validity is HTMT. The suggested value for HTMT should be less than 0.85 as conservative and 0.90 as commonly accepted but a little lenient approach (Hair Jr et al., 2016). In our study, we meet the threshold for HTMT (refer Table 5).

Table 4

Fornell- Larcker Criterion

\begin{tabular}{ccccc}
\hline & DA & HP & NS & TI \\
\hline DA & -0.795 & & & \\
HP & $-0.220^{*}$ & -0.758 & & \\
NS & $0.376^{*}$ & $-0.516^{*}$ & -0.714 & \\
TI & $-0.258^{*}$ & $0.763^{*}$ & $-0.617^{*}$ & -0.899 \\
\hline
\end{tabular}


Table 5

Discriminant Validity

\begin{tabular}{ccccc}
\hline & DA & HP & NS & TI \\
\hline DA & & & & \\
HP & 0.234 & & & \\
NS & 0.474 & 0.591 & & \\
TI & 0.247 & 0.844 & 0.685 & \\
\hline
\end{tabular}

\section{Testing the Direct and Moderating Relationships}

We have used PLS bootstrapping 5000 sampling technique to test the hypotheses in SmartPLS3. Table 6 and Figure 3 depict the relationships between the independent variable $(\mathrm{HP})$, moderating variable (NS) and (DA) and the dependent variables (TI).

\section{Figure 3}

Independent, Dependent and Moderating Variables

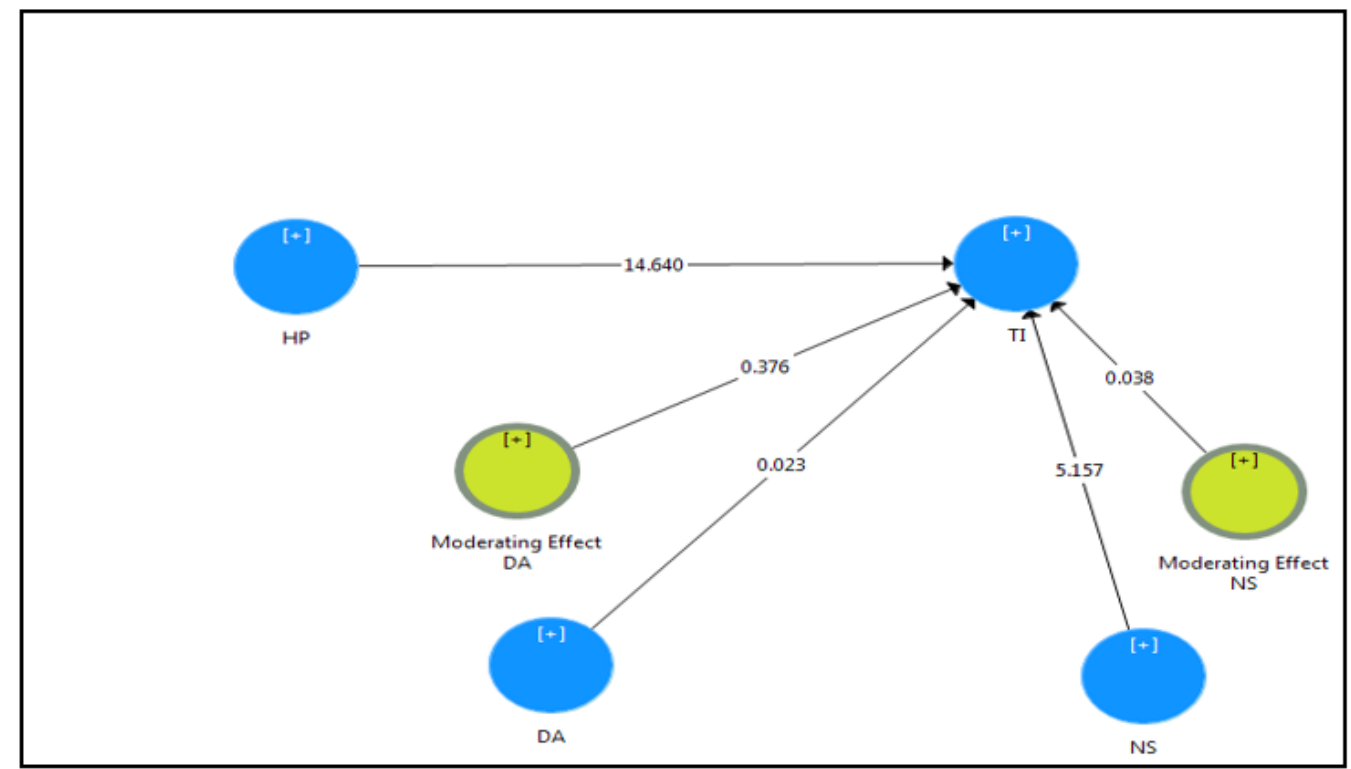

Table 6

Relation between Independent, Moderating and Dependent Variables

\begin{tabular}{llccccc}
\hline & Relationship & OS & SD & T Value & P Values & Decision \\
\hline H1 & HP - > TI & 0.607 & 0.041 & 14.64 & 0.000 & Supported \\
H2 & NS Moderator -> TI & 0.002 & 0.047 & 0.038 & 0.970 & Not Supported \\
H3 & DA Moderator -> TI & -0.025 & 0.068 & 0.376 & 0.707 & Not Supported \\
\hline
\end{tabular}

Based on the above results, we find that hierarchical plateau (H1) has a positive impact on turnover intention ( $\mathrm{t}$-value $>1.96, \mathrm{p}<0.05$ ). It can also be deduced from the above that there exists a direct relationship between the independent and dependent variables. P-J 
fit is the moderating variable here and based on the data, it is evident that the hypothesis need supplies (H2) and demand abilities (H3) acts as a moderator in the relation between hierarchical plateau and turnover intention is not supported (t-value $<1.96, \mathrm{p}>0.05$ ).

\section{Discussion}

This study aims to examine the impact of hierarchical plateau on turnover intention with moderating role of person job-fit facet. Nowadays, managing hierarchical plateau has become a serious concern for employees and HR professionals. Following many years of research and big number of investigated publications; employees' turnover has been and still stays an important topic of study (Hom, Lee, Shaw, \& Hausknecht, 2017). High turnover is costly for organizations and also adversely affect employee's mental mindset where a worker cannot perform the best in a company when does not see any future growth in the current organization (Memon, Salleh, \& Baharom, 2016). Many previous studies have been conducted on turnover intention and very few have come up with impact of hierarchical plateau. This research was aimed to examine whether hierarchical plateau has significant impact on turnover intention and it proved positively. Results indicated that hierarchical plateau has significant impact on turnover intention and hypothesis is accepted with T-value greater than 1.96 and P-values less than 0.05. Furthermore, moderating role of person job fit facet with two different constructs was applied to see which one (demand abilities or need supplies) moderates relationship between independent and dependent variable. Results show that neither demand abilities nor need supplies moderates the relationship and both hypotheses got rejected with $\mathrm{P}$-values greater than 0.05 . It means if employees' demands are to be met like skills, time, and knowledge to build good fit between organization and individual; again, one will think to quit company. Similarly, if need supplies fit occurs; means an organization meets an employee's needs, desires and preferences; again, employee will intent to leave an organization.

The current study also suggests that one of the significant question confronting the tomorrow organizations culture is the way to plan and manage employees in a manner that fulfill not only demands and needs of person but there are certain other factors which organizations has to keep in mind if companies want to retain their skilled assets. When future promotions are unlikely at current position, organization needs to think out of box rather facing the cost of leaving experienced employees and cost of hiring and training of new employees (McCleese \& Eby, 2006).

\section{Managerial Implications and Recommendations}

This research will act a valuable source for management of organizations who are in continuous efforts to retain their key skilled employees. The importance of hierarchical plateau of employees without any doubt leads to big challenge for companies which failed to have their experienced employees. There are several reasons which make employees' mindset change when their expectations are not being fulfilled by current management. Every leader must know the personal and professional objectives of his employees (Mancia et al., 
2007). Managers and leaders can have important insight from this research to understand hierarchical plateau has become current dilemma at every organization in the whole world. Turnover intention is the possibility of employees leaving the company that they purposely and intentionally plan on not receiving future promotions by the company (Coetzee \& van Dyk, 2018). It is something that cannot be fully stopped by management however it may be reduced at certain level. Furthermore, the current study of this research not only helps HR practitioners to retain their qualified and experienced employees but also minimize the costs associated with hiring, training and etc. The effective and efficient processes by top management must be followed in a timely manner which will make company and coworkers victorious in the long term. For example, scales of questions which were filled by respondents would realize them to think where they actually stand and whether they can be good assets for organization after evaluating their strengths and weakness. Lastly, this research has been made in giving overall insight for management of organizations of Pakistan that world has changed drastically and things are not the same which used to be. New ways of thinking processes are to be taken if organization wants to retain their old employees thus it's time to think differently if organizations want to have competitive edge in market. Turnover intention is one of the most important hindrances towards success of company and accomplishment of its mission and vision thus company's plans must be smart and fast to make their employees lifelong attachment with them. Continuous discussion with experienced employees, listening their issues and performance appraisal is the time when employees' concerns should be given proper attention to reduce their stress level.

\section{Limitations and Future Avenue}

This study has been conducted keeping in view of previous researches been done in relation of hierarchical plateau and turnover intention. The current study has been limited to three different industry sectors of Karachi, Pakistan. As whole population was not approachable due to limited time frame of 4-5 months, therefore total 260 questionnaires were filled by respondents; out of which 37 questionnaires were nullified as those employees were on job (1-2 years) and sample size of those respondents targeted for analysis which has spent at least 3 years on that current position. Therefore, 223 employees' respondent's data of different sectors within Karachi were analyzed. Firstly, a significant limitation in this study is the emergence of Halo Error due to the responses from the participants based on judgments rather than actual facts (Speklé \& Widener, 2018). This has affected the linkage amongst the variables and can profess to be counterfeit result of general positive responses. Secondly, important limitation could be the perception of the respondents, which is of major concern. The current research is cross sectional and is limited to four months' time only; hence it is not possible to cover all aspects related to the area. Therefore, a longitudinal research on the same area is suggested in the future. Lastly, it is recommended to adopt other moderating variables for future research studies as person job fit facet (need supplies and demand abilities) did not moderate the relationship between hierarchical plateau and turnover intention. Different mediating variables like job satisfaction, empowerment etc can also be taken to check increase level of relationship between these two variables independent and dependent. 


\section{References}

Ab Hamid, M., Sami, W., \& Sidek, M. M. (2017). Discriminant validity assessment: Use of fornell \& larcker criterion versus htmt criterion. In Journal of physics: Conference series (Vol. 890).

Afsar, B., Shahjehan, A., \& Shah, S. I. (2018). Frontline employees' high-performance work practices, trust in supervisor, job-embeddedness and turnover intentions in hospitality industry. International Journal of Contemporary Hospitality Management.

Atitsogbui, J., \& Amponsah-Tawiah, K. (2019). Turnover intention and job fit among nurses in Ghana: Does psychological climate matter? Nursing Open, 6(2), 546-557.

Awan, A. G., \& Tahir, M. T. (2015). Impact of working environment on employee's productivity: A case study of banks and insurance companies in Pakistan. European Journal of Business and Management, 7(1), 329-345.

Bani-Melhem, S., Quratulain, S., \& Al-Hawari, M. A. (2020). Customer incivility and frontline employees' revenge intentions: interaction effects of employee empowerment and turnover intentions. Journal of Hospitality Marketing \& Management, 29(4), 450-470.

Bitzer, S., \& Van Der Smagt, P. (2006). Learning emg control of a robotic hand: towards active prostheses. In Proceedings 2006 IEEE International Conference on Robotics and Automation, 2006. ICRA 2006. (pp. 2819-2823).

Bollen, N. P., \& Busse, J. A. (2001). On the timing ability of mutual fund managers. The Journal of Finance, 56(3), 1075-1094.

Bretz Jr, R. D., Boudreau, J. W., \& Judge, T. A. (1994). Job search behavior of employed managers. Personnel Psychology, 47(2), 275-301.

Chang, H.-T., Chi, N.-W., \& Chuang, A. (2010). Exploring the moderating roles of perceived person-job fit and person-organisation fit on the relationship between training investment and knowledge workers' turnover intentions. Applied Psychology, 59(4), $566-593$.

Chi, N.-W., \& Pan, S.-Y. (2012). A multilevel investigation of missing links between transformational leadership and task performance: The mediating roles of perceived person-job fit and person-organization fit. Journal of Business and Psychology, 27(1), $43-56$.

Chin, W. W., et al. (1998). The partial least squares approach to structural equation modeling. Modern Methods for Business Research, 295(2), 295-336.

Coetzee, M., \& van Dyk, J. (2018). Workplace bullying and turnover intention: Exploring work engagement as a potential mediator. Psychological Reports, 121(2), 375-392.

Drucker-Godard, C., Fouque, T., Gollety, M., \& Le Flanchec, A. (2015). Career plateauing, job satisfaction and commitment of scholars in french universities. Public Organization Review, 15(3), 335-351.

Ertürk, A., \& Vurgun, L. (2015). Retention of it professionals: Examining the influence of empowerment, social exchange, and trust. Journal of Business Research, 68(1), $34-46$.

Ference, T. P., Stoner, J. A., \& Warren, E. K. (1977). Managing the career plateau. Academy of Management Review, 2(4), 602-612. 
Fornell, C., \& Larcker, D. F. (1981). Structural equation models with unobservable variables and measurement error: Algebra and statistics. Sage Publications Sage CA: Los Angeles, CA.

Ghayas, M. M., Siddiqui, S. J., et al. (2012). Impact of job satisfaction on turnover intentions in the pharmaceutical industry of karachi. South Asian Journal of Management Sciences, 6(2), 42-49.

Greguras, G. J., \& Diefendorff, J. M. (2009). Different fits satisfy different needs: Linking person-environment fit to employee commitment and performance using selfdetermination theory. Journal of Applied Psychology, 94 (2), 465.

Hair Jr, J. F., Hult, G. T. M., Ringle, C., \& Sarstedt, M. (2016). A primer on partial least squares structural equation modeling (PLS-SEM). Sage publications.

Holtom, B. C., Mitchell, T. R., Lee, T. W., \& Inderrieden, E. J. (2005). Shocks as causes of turnover: What they are and how organizations can manage them. Human Resource Management: Published in Cooperation with the School of Business Administration, The University of Michigan and in alliance with the Society of Human Resources Management, 44(3), 337-352.

Hom, P. W., Lee, T. W., Shaw, J. D., \& Hausknecht, J. P. (2017). One hundred years of employee turnover theory and research. Journal of Applied Psychology, 102(3), 530.

Hossain, T., \& Shirazi, H. (2018). Quality of work life among women employees working in RMG Sector of Bangladesh. Global Disclosure of Economics and Business, 7(1), $27-40$.

Juhdi, N., Pa'wan, F., \& Hansaram, R. M. K. (2013). Hr practices and turnover intention: The mediating roles of organizational commitment and organizational engagement in a selected region in Malaysia. The International Journal of Human Resource Management, 24(15), 3002-3019.

Kremer, M., Brannen, C., \& Glennerster, R. (2013). The challenge of education and learning in the developing world. Science, 340(6130), 297-300.

Kristof-Brown, A. L., Zimmerman, R. D., \& Johnson, E. C. (2005). Consequences of individuals'fit at work: A meta-analysis of person-job, person-organization, persongroup, and person-supervisor fit. Personnel Psychology, 58(2), 281-342.

Lauver, K. J., \& Kristof-Brown, A. (2001). Distinguishing between employees' perceptions of person-job and person-organization fit. Journal of Vocational Behavior, 59(3), $454-470$.

Lin, Y.-c., Chen, A. S.-y., \& Lai, Y.-t. (2018). Breach or bridge your career? understanding the relationship between career plateau and internal employability. Personnel Review.

Lofquist, L. H., \& Dawis, R. V. (1984). Research on work adjustment and satisfaction: Implications for career counseling. Handbook of Counseling Psychology, 216-237.

Mancia, G., De Backer, G., Dominiczak, A., Cifkova, R., Fagard, R., Germano, G., ... others (2007). 2007 guidelines for the management of arterial hypertension: The task force for the management of arterial hypertension of the european society of hypertension (ESH) and of the european society of cardiology (ESC). European Heart Journal, 28(12), 1462-1536.

McCleese, C. S., \& Eby, L. T. (2006). Reactions to job content plateaus: Examining 
role ambiguity and hierarchical plateaus as moderators. The Career Development Quarterly, 55(1), 64-76.

Memon, M. A., Salleh, R., \& Baharom, M. N. R. (2016). The link between training satisfaction, work engagement and turnover intention. European Journal of Training and Development.

Memon, M. A., Salleh, R., Baharom, M. N. R., \& Harun, H. (2014). Person-organization fit and turnover intention: The mediating role of employee engagement. Global Business \& Management Research, 6(3).

Patra, S. M., Chakraborty, S., Shahane, G., Prasanna, X., Sengupta, D., Maiti, P. K., \& Chattopadhyay, A. (2015). Differential dynamics of the serotonin1a receptor in membrane bilayers of varying cholesterol content revealed by all atom molecular dynamics simulation. Molecular Membrane Biology, 32(4), 127-137.

Rahman, A., Naqvi, S., \& Ramay, M. I. (2008). Measuring turnover intention: A study of it professionals in Pakistan. International Review of Business Research Papers, $4(3), 45-55$.

Ringle, C. M., Wende, S., \& Becker, J.-M. (2015). Smartpls 3. Boenningstedt: SmartPLS $\mathrm{GmbH}$.

Speklé, R. F., \& Widener, S. K. (2018). Challenging issues in survey research: Discussion and suggestions. Journal of Management Accounting Research, 30(2), 3-21.

Tetrick, L. E., \& LaRocco, J. M. (1987). Understanding, prediction, and control as moderators of the relationships between perceived stress, satisfaction, and psychological well-being. Journal of Applied Psychology, 72(4), 538.

Veiga, J. F. (1981). Plateaued versus nonplateaued managers: Career patterns, attitudes, and path potential. Academy of Management Journal, 24(3), 566-578.

Wurzelbacher, S. J., Al-Tarawneh, I. S., Meyers, A. R., Bushnell, P. T., Lampl, M. P., Robins, D. C., ... Raudabaugh, J. A. (2016). Development of methods for using workers' compensation data for surveillance and prevention of occupational injuries among state-insured private employers in Ohio. American Journal of Industrial Medicine, 59(12), 1087-1104.

Xie, B., Xin, X., \& Bai, G. (2016). Hierarchical plateau and turnover intention of employees at the career establishment stage. Career Development International.

Zhu, W., May, D. R., \& Avolio, B. J. (2004). The impact of ethical leadership behavior on employee outcomes: The roles of psychological empowerment and authenticity. Journal of Leadership \& Organizational Studies, 11(1), 16-26. 